\title{
A JUSTIÇA POPULAR E SEUS ATOS JURÍDICOS: O TRIBUNAL E SEUS REGIMES DE VERDADE NA (DES)QUALIFICAÇÃO DAS SUBJETIVIDADES
}

\author{
Raquel Célia Silva de Vasconcelos ${ }^{1}$
}

\begin{abstract}
RESUMO:
Este artigo analisa a justiça popular e seus atos jurídicos conduzidos pelo Tribunal e seus regimes de verdade. A justiça popular conduzida pelo tribunal representa os interesses da classe dominante ao legitimar a relação direito-justiça no seu exercício de poder. É uma pesquisa bibliográfica com viés exploratório dos textos de Foucault e a contribuição de outros autores. "Sobre a Justiça Popular", texto foucaultiano, que centraliza as discussões sobre justiça, poder, violência e direito na formação do sistema judiciário ocidental. O Estado com uso da violência expressa o poder como controle do corpo social a partir de seu enquadramento jurídico determinado pelo discurso de justiça popular emitido pelo Tribunal. Em "Sobre a Justiça Popular" Foucault aponta a relação saber-poder do sistema judiciário concebido ao Tribunal que discursa sobre justiça na dimensão do ordenamento imposto pelo direito legitimando as ações do Estado. A justiça popular sob o domínio do Tribunal favorece, manipula e molda as massas. As reflexões foucaultianas acerca dos desdobramentos da ação jurídica instituída nas relações legitimadas pela violência na imposição da ordem são elucidações que direta e indiretamente perpassam discussões acerca dos discursos de verdade jurídico atravessando o saber como exercício de poder. Os atos da Justiça Popular e o Estado estão determinados pelo Tribunal que estabelece os critérios de sua concepção de justiça. Justiça e Poder no exercício das relações da prática judicial são engrenagens na efetivação dos critérios de definição entre meios e fins justos a partir das ações arbitrárias do aparelho de Estado junto à população. O poder bem como a biopolítica são instâncias que delimitam a vida nua (mera vida) da população em situação de rua. Vida atravessada pela linha tênue entre o mundo dos corpos que devem ser cuidados e o mundo daqueles em que o estatuto de vida nua estão fora da jurisdição humana de modo tal que a violência cometida contra eles não constitui nenhuma violação.
\end{abstract}

Palavras-chave: Poder. Verdade. Tribunal. Justiça Popular. População.

\section{THE PEOPLE'S JUSTICE AND ITS LEGAL ACTS: THE COURT AND ITS TRUE REGIMES IN THE (DES) QUALIFICATION OF SUBJECTIVES}

\begin{abstract}
:
This article analyzes popular justice and its legal acts conducted by the Court and its regimes of truth. The court-run popular justice represents the interests of the ruling class by legitimizing the right-justice relationship in its exercise of power. It is a bibliographical research with an exploratory bias of the texts of Foucault and the contribution of other authors. "About Popular Justice," a Foucauldian text that centralizes discussions on justice, power, violence and law in the formation of the Western judicial system. The State with the use of violence expresses power as control of the social body from its legal framework determined by the speech of popular justice issued by the Court. In "About the People's Justice" Foucault points out the knowledge-power relationship of the judiciary system conceived to the Court that speaks about justice in the dimension of the order imposed by the law legitimizing the actions of the State. The popular justice under the dominion of the Court favors, manipulates and shapes the masses. Foucauldian reflections about the consequences of legal action instituted in relations legitimized by violence in the imposition of order are elucidations that directly and indirectly pass through discussions about the discourses of legal truth crossing knowledge as an exercise of power. The acts of the People's Justice and the State are determined by the Court that establishes the criteria of its conception of justice. Justice and Power in the exercise of relations of judicial practice are gears in the effectiveness of the criteria of definition between means and just ends from the arbitrary actions of the state apparatus with the population. Power as well as biopolitics are instances that delimit the bare life (mere life) of the street population. Life crossed by the fine line between the world of bodies to be cared for and the world of those in which the statute of bare life are outside of human jurisdiction in such a way that the violence
\end{abstract}

\footnotetext{
${ }^{1}$ Filósofa e doutora em educação, atuando como artista plástica e professora Titular I da Faculdade Metropolitana da Grande Fortaleza - Fametro e do Instituto Federal do Ceará. Email: raquelcsvasconcelos@gmail.com.
} 
committed against them is not a violation.

Keywords: Power. Truth. Court. Popular Justice. Population.

\section{Introdução}

As elucidações foucaultianas provocam uma análise desafiadora ao permitir reflexões acerca dos desdobramentos da ação jurídica a partir do poder instituído nas relações, muitas vezes, legitimadas pela violência na imposição da ordem. São elucidações que diz respeito ao texto, "Sobre a Justiça Popular", que direta e indiretamente perpassam discussões foucaultianas acerca da verdade e poder, atravessando o saber como exercício de poder.

No referido texto Foucault aponta a relação saber-poder do sistema judiciário concebido ao tribunal que discursa sobre justiça na dimensão do ordenamento imposto pelo direito legitimando as ações do Estado. Foucault assinala que o tribunal não é a expressão natural da justiça popular como deveria ser. Na verdade ele tem sua maior expressão na forma reinscrição do discurso que favorece, manipula e molda a justiça popular. Nessa perspectiva, este artigo traz dois momentos de discussão, o primeiro, Os Atos de Justiça Popular e o Estado, discorre sobre o controle que o Tribunal exerce sobre a justiça popular, sobretudo no tocante aos critérios estabelecidos acerca de sua concepção de justiça.

No segundo, Justiça e Poder: Exercício das Relações, analisa a prática judicial com suas novas engrenagens na efetivação dos critérios de definição entre meios e fins justos a partir das ações arbitrárias do aparelho de Estado. Foucault põe em xeque a forma como a justiça popular é conduzida pelo poder judiciário.

No terceiro, Poder e seus jogos de força na (des)qualificação da população, investiga o poder como atravessamento do mundo dos direitos e a biopolítica como definidora do mundo das 'exceções' ao afirmar o cálculo que o poder faz sobre a vida, quando o poder delineia seu jogo de forças. Este não está restrito a um único ponto de origem cujo campo de forças são desiguais e móveis, resultante de um poder que produz relações imanentes a outras formas de relações em que os envolvidos nelas mantêm entre si efeitos imediatos das partilhas, desigualdades e desequilíbrios imersos nos campos econômico, gênero e nos que perpassam as tramas complexas do tecido social.

\section{Os Atos de Justiça Popular e o Estado}

A hipótese central de Foucault, em seu texto "Sobre a justiça popular", "é que

\begin{tabular}{|c|c|c|c|c|}
\hline Rovista Dialectus & Ano 4 & n. 11 & Agosto - Dezembro 2017 & p. $145-157$ \\
\hline
\end{tabular}


o Tribunal não é a expressão natural da justiça popular, mas, pelo contrário, tem por função histórica reduzi-la, dominá-la, sufocá-la, reescrevendo-a no interior de instituições características do aparelho de Estado" (Foucault, 1979, p. 87). Em sua abordagem Foucault discorre sobre a possibilidade de deslocamento da justiça ao domínio das classes sociais uma vez que reconhece a justiça como instrumento de resistência importante e autêntico que pode beneficiar as classes oprimidas. Para Foucault, no entanto, a questão da justiça perpassa todas as lutas sociais, mas aconselha que "ao invés de pensar a luta social em termos de 'justiça', deve-se enfatizar a justiça em termos de luta social" (1979, p. 89).

Segundo Foucault (1979), quando uma sociedade de classe decide sobre o justo ou injusto, são tomadas por uma instância que se diz neutra como o tribunal judiciário e a concepção social de justiça. Esta, no entanto, corresponde aos interesses da classe que a instituiu e a controla, pois, o tribunal, enquanto aparelho do Estado, tem como função dividir as massas, sobretudo porque "a justiça popular reconhece na instância judiciária um aparelho de Estado representante do poder público e instrumento do poder de classe" (Foucault, 1979, p. 93).

Contudo, tal decisão pressupõe determinações de governos que discursam sempre contra opositores ou não opositores a partir da tutela da desordem, cuja saída é sempre a imposição da ordem através da violência como essencial a manutenção do poder pelo Estado. Como diria Stuart Mill (apud Arendt, 2016, p. 55), “a primeira lição da civilização [é] aquela da obediência, [...] dois estados de inclinações [...] um, o desejo de exercer poder sobre os outros; o outro, a falta de inclinação para sofrer o exercício do poder."

Ao se referir à uma instância neutra, Foucault denuncia as decisões tomadas pelo juiz, que, no momento do veredito final, estabelece discursos de verdade que apontam a falácia do posicionamento neutro durante o julgamento. O juiz, no entanto, assume a posição de autoridade que perpassa a ordem como imposição da obediência. $\mathrm{Na}$ concepção foucaultiana a ideia de autoridade neutra, cuja decisão perpassa as duas partes com base numa justiça com valor absoluto, é totalmente contrária à ideia de justiça popular.

$\mathrm{Na}$ prática da justiça popular, para o autor, existem apenas as massas e seus inimigos uma vez que não existe um elemento neutro na autoridade do juiz enquanto instituição política, pois "todas as instituições políticas são manifestações e materializações do poder; elas se petrificam e decaem tão logo o poder vivo do povo

\begin{tabular}{|l|l|l|l|l|}
\hline Qevista Dialectus & Ano 4 & n. 11 & Agosto-Dezembro 2017 & p. $145-157$
\end{tabular}


deixa de sustentá-las" (Arendt, 2016, p. 57). Portanto, Foucault aponta que a subversão do poder judiciário se dá pelas classes oprimidas como atos de justiça popular em resistência e superação à opressão exercida pela classe dominadora.

Vale ressaltar que os oprimidos decidem punir ou reeducar seus inimigos, cujas decisões têm como base a experiência dos danos que sofreram e a forma como foram prejudicados. Como afirma Brandão (2010, p. 7):

A classe oprimida não inicia uma guerra contra a classe opressora porque considera tal guerra justa, mas porque ela quer, finalmente, tomar o poder. Por outro lado, [...], a noção de justiça pode funcionar como uma demanda dos oprimidos ou como uma justificativa para tal demanda".

Para Foucault, a justiça popular deve promover o esclarecimento da política e a eliminação da alienação e da divisão ideológica entre diferentes camadas das classes populares, para que as pessoas possam ter uma melhor visão do que acontece ao seu redor, sem que sejam induzidos pelo poder da classe dominante. Isto significa que a noção de justiça como uma demanda social dos oprimidos aponta para uma dimensão de desiguais na tomada de decisão na efetivação da justiça.

$\mathrm{Na}$ justiça popular existem apenas as massas e seus inimigos. Aqui inexiste um elemento neutro que decide com autoridade. Tão pouco, os oprimidos se valem de uma noção de justiça abstrata e universal, quando decidem punir ou reeducar seus inimigos. Sua decisão tem como base a experiência concreta. Isto é, os danos que sofreram e a forma como foram prejudicados. (Brandão, 2010, p. 8)

Ademais a tradição filosófica ocidental sempre estabeleceu discussões acerca da questão da justiça, sobretudo vista como exercício político correspondente aos costumes do grupo social. Sempre fora uma preocupação dos filósofos estabelecer o conceito de justiça na dimensão da convivência social. Isto significa, como assinala Brandão, que a tradição mais clássica da filosofia estabeleceu duas classificações acerca do conceito de justiça:

Na primeira, justiça se refere ao sujeito ou ao seu comportamento em relação à norma. Na outra, a justiça é tomada como meio para um bem maior. Esta análise nos deu critérios para reduzir a amplitude do campo de investigação filosófica sobre a justiça nas obras de Foucault. (Brandão, 2010, p. 2)

As duas concepções de justiça ficam restritas ao campo de ação individual centrada somente no indivíduo, dificultando estabelecer um conceito de justiça como exercício que se dá simultaneamente nas dimensões tanto individual quanto coletiva sob

\begin{tabular}{|c|c|c|c|c|}
\hline Rovista Dialectus & Ano 4 & n. 11 & Agosto - Dezembro 2017 & p. $145-157$ \\
\hline
\end{tabular}


o julgo do poder também como exercício presente nas relações. Tal exercício não escolhe credo, classes social e econômica, tampouco define política desvinculado do poder-violência comum ao grupo.

\section{Justiça e Poder: Exercício das Relações}

A justiça em Foucault toma uma amplitude para pensar o poder como exercício que se dá nas relações sociais, apontando que a própria justiça é também um exercício. Em "Vigiar e Punir", Foucault esclarece que "a punição passa por mudanças, tornando-se a parte mais velada do processo penal, provocando várias consequências: deixa o campo da percepção quase diária e entra no da consciência abstrata; sua eficácia é atribuída à sua fatalidade não à sua intensidade visível” (1987, p. 13).

Portanto, a certeza da punição desvia o acusado do crime que não se dá mais na dimensão do suplício, mas aos olhos do Poder Judiciário que tem na justiça popular sua maior expressão participativo do povo. A nova instância judicial tem na lei sua nova forma de "punição" legal que obedece a novas engrenagens utilizadas no âmbito de uma justiça legal do ponto de vista discursivo, como uma prática que não aplica mais a violência como exercida no suplício como ordem estabelecida pelo poder soberano.

De fato, uma das mais óbvias distinções entre poder e violência é que o poder sempre depende de números, enquanto a violência, até certo ponto, pode operar sem eles, porque se assenta em implementos. Um domínio legalmente irrestrito da maioria, uma democracia sem Constituição, pode ser muito formidável na supressão dos direitos das minorias e muito efetivo em sufocar o dissenso sem qualquer uso da violência. Mas isso não significa que violência e poder sejam o mesmo (Arendt, 2016, p. 58).

Por essa razão, assinala Foucault, "a justiça não mais assume publicamente a parte de violência que está ligada a seu exercício" (1987, p. 13). Na verdade, a prática judicial, a partir das novas engrenagens, tem como objetivo a docilização dos corpos que impregna o jusnaturalismo na tomada de decisão acerca da validade e atuação do direito positivo se sobrepondo ao direito natural, especialmente aos critérios de definição entre meios e fins justos.

À tese, defendida pelo direito natural, do poder como dado da natureza, se opõe diametralmente a concepção do direito positivo, que considera o poder como algo que se criou historicamente. Se o direito natural pode avaliar qualquer direito existente apenas pela crítica de seus fins, o direito positivo pode avaliar qualquer direito que surja apenas pela crítica de seus meios. Se a justiça é o critério dos fins, a legitimidade é o critério dos meios. (Benjamin, 1986, p. 160).

\begin{tabular}{|l|l|l|l|l|}
\hline Qenista Dialectus & Ano 4 & n. 11 & Agosto - Dezembro 2017 & p. $145-157$ \\
\hline
\end{tabular}


Para muitos a justiça exerce somente uma função, mas, para Foucault, a forma como a justiça popular é conduzida pelo poder judiciário levanta desconfiança porque sua efetivação se encontra da ordem do discurso. Isto significa que a prática da justiça é mero discurso de verdade, favorecendo a classe dominante que determina as ações do Estado legitimadas por fins e meios, muitas vezes, injustos apontando naquelas ações um paradoxo. Trata-se de concepção de justiça determinando quais os indivíduos beneficiados tendo como pressuposto o Direito, legislador dos sujeitos, cujo direito de pedir justiça pressupõe estar inscrito em uma jurisdição determinada pelo Direito.

Tal convicção explicitamente assumida pelo totalitarismo, de que os seres humanos são supérfluos e descartáveis, representa uma contestação frontal à idéia do valor da pessoa humana enquanto valor-fonte da legitimidade da ordem jurídica, como formulada pela tradição, senão como verdade pelo menos como conjectura plausível da organização da vida em sociedade. (Lafer, 1997, p. 57).

$\mathrm{Na}$ verdade, as ações do Estado delineiam discursos jurídicos que, muitas vezes, conduz a tomada de posição contrária à justiça popular que deveria ser um exercício do poder enquanto instrumento de transformação social. Por isso, Foucault questiona a justiça popular dentro dos tribunais, pois quem a compõe comunga com os aparelhos do Estado que parece deter uma espécie de poder mais elevado frente à classe subjugada, cujo poder não se inscreve nos discursos de verdades determinados no tribunal.

Para Foucault a justiça popular ocupada pelos que lutam por justiça reforça sua ideia de que o poder transita, ele não está sob o controle do Estado e de suas instituições, mas está nas relações, o Tribunal apenas faz transparecer às massas que ele o pertence. Há uma tentativa de fazer crer que o poder e a força (da lei) são o mesmo e partem do indivíduo ou de quem o representa. Na verdade, como assinala Arendt, "o poder corresponde à habilidade humana não apenas para agir, mas também para agir em concerto. O poder nunca é propriedade de um indivíduo; pertence a um grupo e permanece em existência apenas enquanto o grupo se conserva unido" (2016, p. 60).

Dessa forma, poder e justiça popular têm no direito natural a legitimidade do uso de meios violentos para fins justos, pois "o direito natural não vê problema nenhum no uso de meios violentos para fins justos; [...]. Segundo essa concepção [...], a violência é um produto da natureza, por assim dizer, uma matéria-prima utilizada sem problemas, a não ser que haja abuso da violência para fins injustos” (Benjamin, 1986, p. 160).

\begin{tabular}{|c|c|c|c|c|}
\hline Qovista Dialectus & Ano 4 & n. 11 & Agosto - Dezembro 2017 & p. $145-157$ \\
\hline
\end{tabular}


Nesse aspecto, evidencia-se o quanto é preciso repensar o sentido da distinção do poder em legítimo e ilegítimo porque nunca houve uma distinção clara. Para Foucault uma justiça popular, em suas funções e atribuições, defende os interesses do aparelho de Estado que tem no Tribunal sua maior expressão, isso faz parte da história da criação do judiciário no Ocidente.

Nas sociedades como a nossa, pelo contrário, o aparelho de justiça foi um aparelho de Estado extremamente importante cuja história foi sempre mascarada. Faz-se a história do direito, da economia, mas a história da justiça, da prática judiciária, do que foi efetivamente um sistema penal, do que foram os sistemas de repressão, disso fala-se raramente. Ora, creio que a justiça como aparelho de Estado teve na história uma importância capital (Foucault, 1979, p. 49-50).

Foucault esclarece que a sociedade francesa a justiça e o Estado são aparelhos de repressão fundamentais, cuja história deles é pouco falada, sobretudo a contribuição desses aparelhos na constituição da prática judiciária e do sistema penal. Este introduz as contradições das massas ao contrapor as classes proletária e não proletária, pois historicamente quem determinava a pena reprimiu as revoltas populares através da força militar.

\footnotetext{
O sistema penal teve por função introduzir um certo número de contradições no seio das massas e, em particular, uma contradição maior: opor os plebeus proletarizados aos plebeus não proletarizados. A partir de uma certa época, o sistema penal, que tinha essencialmente uma função fiscal na Idade Média, dedicou-se à luta anti-sediciosa. A repressão das revoltas populares tinha sido até então sobretudo tarefa militar. Foi em seguida assegurada ou melhor, prevenida, por um sistema complexo justiça-polícia-prisão (Foucault, 1979, p. 50).
}

Nesse sentido, o poder apenas na função repressora é frágil, embora seja isso que o Estado faz, aliás ele conduz a falsa crença em um poder repressor, facilitando, assim, a estagnação da sociedade. É fato que as relações de poder, enquanto exercício do poder, favorece transformações sociais e reduz os efeitos dos discursos de verdades que as grandes instituições, sobretudo o aparelho de Estado, impõe. Foucault esclarece que a justiça no âmbito do Tribunal não permite a efetivação da justiça popular porque o discurso jurídico está em defesa dos interesses da classe dominante.

Por certo, o poder em Foucault tanto reprime como produz efeitos de verdade e saber. Ele deve ser captado em seus polos extremos, em suas ramificações e "nas suas formas e instituições mais regionais e locais, [...] ultrapassando as regras de direito que o organizam e delimitam [...], captar o poder na extremidade cada vez menos jurídica de seu exercício." (Foucault, 1979, p. 182).

\begin{tabular}{|c|c|c|c|c|}
\hline Revista Dialectus & Ano 4 & n. 11 & Agosto - Dezembro 2017 & p. $145-157$ \\
\hline
\end{tabular}


No tocante à tríade poder, direito e verdade, Foucault aponta que tanto o direito quanto o poder se apresentam na colocação e movimentação do corpo social, instituindo aquele como verdade por meio do discurso e do movimento do Tribunal com seu pronunciamento jurídico determinando às massas a quem devem obediência. Esta é assumida pelo corpo da sociedade sem nenhuma consciência e/ou reflexão,

\begin{abstract}
para assinalar simplesmente, não o próprio mecanismo da relação entre poder, direito e verdade, mas a intensidade da relação e sua constância, digamos isto: somos forçados a produzir a verdade pelo poder que exige essa verdade e que necessita dela para funcionar, temos de dizer a verdade, somos coagidos, somos condenados a confessar a verdade ou encontrá-la. (Foucault, 1999, p. 29)
\end{abstract}

Nesse aspecto, entende-se que o poder como uma ação sobre demais ações. Assim, as relações de poder são marcadas por um processo de disciplinarização, pois "a disciplina traz consigo uma maneira específica de punir, que é apenas um modelo reduzido do tribunal" (Foucault, 1987, p. 149) A disciplina evidencia as relações de poder ao permitir a visibilidade da relação opressor-oprimido, pois a tríade poderdireito-verdade torna eficaz a disciplina. Isto aponta para o poder e seus jogos de força quando se evidencia a marginalização da população em situação de rua, pessoas que estão à margem da cidadania, consequentemente à margem da justiça que, por sua vez, permite essa população ter uma vida desqualificada.

\title{
Poder e seus jogos de força na (des)qualificação da população
}

Nesse sentido, o poder e seus jogos de força convergem com a lógica colonialista que expressa o mundo dos direitos e um outro mundo de exceções. $\mathrm{O}$ exercício do poder se encontra em um campo de forças desiguais e móveis, cujas relações são imanentes a outras formas de relação em que indivíduos, grupos e instituições estabelecem entre si (Foucault, 1989). O poder se constitui como "os efeitos imediatos das partilhas, desigualdades e desequilíbrios" produzidos nas relações econômicas, de gêneros e nas que atravessam as tramas complexas do tecido social.

A relação entre poder e dominação identificando o vital e o político está imerso nas questões políticas correspondentes ao domínio público. Isto não seria diferente à população em situação de rua, protagonista da invisibilidade que transitam nos espaços urbanos das metrópoles e vivenciam o neocolonialismo contemporâneo de enunciação e justificação de um no qual alguns têm permissão de viverem e outros são deixados para morrerem. Alguns tem direito a cuidados e à vida, outros são massacrados

\begin{tabular}{|c|c|c|c|c|}
\hline Qovista Qialectus & Ano 4 & n. 11 & Agosto - Dezembro 2017 & p. $145-157$ \\
\hline
\end{tabular}


pro-políticas públicas que deveriam fazê-los viver, mas inversamente são postos fora da jurisdição humana. Constituem vidas que não são levadas em consideração e, se ignoradas, não haverá punição.

A vida na rua corresponde à transição constante de um espaço ao outro, oriundo da demarcação de território entre os grupos que vivenciam a rua como lugar paradoxal, pois está nele é experienciar o medo e a segurança simultaneamente. Esta quando as pessoas que vivem em situação de rua experienciam o temor do grupo opositor e afeição dos que se aglomeram por empatia. A transitoriedade dessas pessoas delineia a falta de fidelidade a um espaço determinado de moradia na rua diante da opressão.

Segundo Marx (2003) a opressão começa no seio familiar a partir da reversão do direito materno, quando, nos primórdios, os filhos estavam restritos a genes maternos. Contudo, com o aparecimento da propriedade privada e a tentativa de sua perpetuação, foi preciso conceber os herdeiros, que, por direito teriam na filiação masculina o direito à hereditariedade paterna, permitindo, assim, a centralização do controle de tudo no masculino. Nesse contexto, homem passa a governar o lar, a explorar o trabalho e o corpo da mulher, esta passa a ser vista como objeto sexual e propicia à mera reprodução.

Por certo, as primeiras formas de opressão facilitaram o aparecimento de outras maneiras opressoras, que estariam vinculadas às razões moral, socioeconômica, política, bem como étnico-racial. Marx (2003) assinala que a exploração e a alienação aumentaram após o aparecimento do Capitalismo, cujo critério central está na obtenção do lucro, intensificando, assim, diversas formas de opressão que conduziu populações à miséria e à marginalização.

Nessa perspectiva, pode-se destacar as pessoas em situação de rua que precisam, a partir do espaço no qual estão situados, dormir ou fazer mendicância. Elas estão em locais que as mesmas necessitam dar significado e ressignificado ao convívio na rua, transformando seu modo de vida e adaptação.

Dessa maneira, a rua como dimensão do espaço público se transforma em lar e esta, na condição de habitação, ressignifica-se em conjunto de relações do homem com o espaço. Um simples banco de praça, uma marquise ou mesmo uma calçada pode definir um pertencimento no qual se garante um nível de satisfação e de autonomia, de certo modo. Assim, a apropriação do espaço público em espaço privado a partir de territorializações e, principalmente de territorialidades propicia um nível de familiaridade e de aconchego, mesmo que a cama seja de concreto. (Robaina, 2012, p. 9)

\begin{tabular}{|c|c|c|c|c|}
\hline Qovista Dialectus & Ano 4 & n. 11 & Agosto - Dezembro 2017 & p. $145-157$ \\
\hline
\end{tabular}


A vida na rua delineia que o capital forja uma espécie de (des)qualificação da vida das pessoas, que além da delimitação de espaço entre os que convivem à situação de rua, também precisam delimitar o processo de migração nas ruas que, direta e indiretamente está vinculada às ações arbitrárias do Estado por meio de suas instituições. O Direito, o Tribunal e a força policial estão a serviço da higienização da cidade, gerando uma espécie de "apartheid social", que, segundo BOBBIO et al, em língua afrikaans, apartheid significa "separação".

\begin{abstract}
Na sua acepção mais comum, pode traduzir-se por 'identidade separada' e designa a política oficial do governo sul-africano no que diz respeito aos direitos sociais e políticos e às relações entre os diversos grupos raciais dentro da União. O apartheid não pode, pois, ser traduzido simplesmente como 'racismo' ou 'discriminação racial', constitui um sistema social, econômico e político - constitucional que se baseia em princípios teóricos e numa legislação ad hoc. (Bobbio et al, 1995, p. 54).
\end{abstract}

Vale ressaltar que as pessoas que escolhem as ruas como moradia fazem a pratica de uma espécie de nomadismo, pois os exercícios da mobilidade constante como sobrevivência não as permitem se fixarem em locais por um longo período de tempo. Com isso, há um intenso fluxo de deslocamento de um lugar para outro, como assinalam Deleuze et al (2002), ao afirmarem que a relação do nômade com o território se dá efetivamente pelos movimentos que o permite constantemente a reterritorialização a partir do seu próprio processo de desterritorialização.

Os autores afirmam que “[...] para o nômade, ao contrário é a desterritorialização que constitui sua relação com a terra, pois se reterritoriza na própria desterritorialização. É a terra que se desterritorializa ela mesma de modo aí encontra um território." (Deleuze et al, 2002, p. 53) Isto aponta que a situação de rua conduz as pessoas à invisibilidade social pelo simples fato de não participarem das estratégias determinadas pelo capital. Elas, muitas vezes, são vistas como ameaçadoras e constantemente são estereotipadas por não se enquadrarem ao mundo produtivo determinado pelo capital, sendo enquadradas às classes perigosas.

As novas classes perigosas são, ao contrário, aquelas consideradas incapacitadas para a reintegração e classificadas como não-assimiláveis, porque não saberiam se tornar úteis nem depois de uma 'reabilitação'. Não é correto dizer que estejam 'em excesso': são supérfluas e excluídas de modo permanente (trata-se de um dos poucos casos permitidos de 'permanência' e também dos mais ativamente encorajados pela sociedade 'líquida'). (Bauman, 2009, p. 22)

\begin{tabular}{|l|l|l|l|l|}
\hline Qevista Dialectus & Ano 4 & n. 11 & Agosto - Dezembro 2017 & p. $145-157$ \\
\hline
\end{tabular}


É fato que a instauração da modernidade líquida, esclarece Bauman, intensificou o individualismo. No início da modernidade a prática da solidariedade estava presente nas ações dos indivíduos que praticavam trocas e relações sociais amistosas. No entanto, na ordem societária líquida o caráter solidário é substituído pela competição acirrada, "os indivíduos se sentem abandonados a si mesmos, entregues a seus próprios recursos - escassos e claramente inadequados” (Bauman, 2009, p. 21).

Nesse aspecto, as pessoas em situação de rua se tornam alvo da "inutilização" que a sociedade impõe àqueles que não trabalham. Elas são ignoradas e indesejadas nos lugares públicos, que pressupõe serem espaços de acesso livre e compartilhados por todos. No entanto, são pessoas que experienciam a sensação de estarem em um espaço que “é 'público' à medida que permite o acesso de homens e mulheres sem que precisem ser previamente selecionados. Nenhum passe é exigido, e não se registram entradas e saídas" (Bauman, 2009, p. 69, crivo do autor).

Dessa forma, a sociedade segrega ao impedir a presença delas em espaços que alcançariam visibilidade, mas os métodos institucionais as marginalizam socialmente. São práticas recorrentes que comungam com ações anti-mendigos, em que a própria cidade é arquitetada para enxotá-las e reprimi-las, materializando-se na prática de retirada de banco das praças, instalação de cerca ou espetos nas calçadas e jardins. Portanto, a situação de rua se constitui em um problema social resultante do pauperismo.

Por certo, a mudança no sistema produtivo gerou uma pobreza e esse mesmo sistema atendo aos interesses do capital a naturaliza a partir de uma estrutura social que não identifica essa pobreza como questão social. Esta se materializa amenizando a responsabilidade de quem ganha com a miséria e de quem diretamente é responsável por ela. Assim, a questão social se torna um problema desvinculado da condição sóciohistórica que a originou após a industrialização, vinculando-a ao processo de culpabilização do próprio indivíduo pela condição em que se encontra e justificando-a como uma vontade divina.

$\mathrm{Na}$ perspectiva de Castel (2012) seria importante uma análise da vulnerabilidade social no atual contexto a partir da instauração de uma "nova questão social". Esta, para o autor, surgiu com o fim do pleno emprego, antes assegurado, nos países detentores do controle do capital, pelo Estado do bem-estar social. Nesse sentido, essa conjuntura socioeconômica conduz a perda da estabilidade laboral resultante do desemprego em massa, gerando um exército de “[...] indivíduos que ocupam na

\begin{tabular}{|c|c|c|c|c|}
\hline Rovista Dialeatus & Ano 4 & n. 11 & Agosto - Dezembro 2017 & p. $145-157$ \\
\hline
\end{tabular}


sociedade uma posição de supranumerários, 'inempregáveis', 'inempregados' ou empregados de um modo precário, intermitente." (Castel, 2012, p. 21) Assim, por meio dessa conjuntura aparecem inúmeras mazelas sociais que são irreconhecíveis pelo paradigma anterior da concepção que se tinha da questão social - desemprego em massa, pobreza extrema e exclusão.

\section{Considerações finais}

Acredito que as discussões sobre o dever da justiça popular permitem lançar um novo olhar à justiça e ao poder, como diz Foucault, um outro olhar às suas deformidades. Isto implica que a deformidade da justiça social não é algo restrito ao sistema judiciário, mas a todos os setores da sociedade que reproduz os discursos de verdades válidos, muitas vezes, proferidos por um "Estado Violência".

O Estado Violência institui e mantém direitos cujos critérios legais obedecem aos poderes sancionados e não sancionados, legítimos e ilegítimos, a partir de sua compreensão jurídica no tocante à sua verdade sobre o que significa fins justos ou injustos. Seus critérios recaem sempre sobre o corpo social que, por sua vez, tornar-se seu espaço de atuação e permanência para suas práticas arbitrárias.

Dessa forma, o Estado e suas instituições mantêm-se unânimes e inquestionáveis no que diz respeito aos arbítrios cometidos. A docilização dos corpos pressupõe um desses arbítrios, pois o controle dos comportamentos e ações para processos de subjetivação são eficazes e determinantes. Portanto, as ações do poder nos âmbitos do direito e da verdade demonstram as formas e os conteúdos que delineiam a relação saber-poder, sujeitando o corpo tanto social quanto individual ao Estado. Assim, o sentido que o Estado atribui às pessoas em situação de rua corresponde à constituição de uma identidade à margem de subjetividades sociais que vivenciam a exclusão imediata da existência na rua que, por sua vez, transforma-se em espaço paradigmático da marginalização constante.

\section{REFERÊNCIAS}

BAUMAN, Zygmunt. Modernidade líquida. Rio de Janeiro: Jorge Zahar Ed., 2001.

. Confiança e medo na cidade. Rio de Janeiro: Jorge Zahar Ed., 2009

BENJAMIN, Walter. Crítica da violência - crítica do poder. In: BENJAMIN, Walter. Documentos de Cultura e Documentos de Barbárie: Escritos escolhidos. Seleção e

\begin{tabular}{|c|c|c|c|c|}
\hline Qovista Dialectus & Ano 4 & n. 11 & Agosto - Dezembro 2017 & p. $145-157$ \\
\hline
\end{tabular}


apresentação de Willi Bolle. São Paulo: Cultrix, 1986, p. 160-175.

BOBBIO, Norberto; MATTEUCCI, Nicola; PASQUINO, Gianfranco. Dicionário de Política. 8. Ed. Brasília: EDUnB, 1995. 2 vols.

BRANDÃO, Caius. A Justiça Popular em Michel Foucault. Artigo publicado na Academia Edu. https://www.academia.edu/1085512/A_justiça_Popular_em_Michel_Foucault.

CASTEL, Robert. As metamorfoses da questão social: uma crônica do salário. 10. ed. Petrópolis: Vozes, 2012.

DELEUZE, Gilles; GUATTARRI, Félix. Mil platôs - capitalismo e esquizofrenia. São Paulo: Ed. 34, 2002.

FOUCAULT, Michel. Em defesa da sociedade: curso no College de France (19751976). São Paulo: Martins Fontes, 1999.

Poder-corpo. In:

Microfísica do Poder. Rio de Janeiro:

Graal, 1979, p 145-152.

Soberania e Disciplina: curso no College de France (14 de Janeiro de 1976). In: __ Microfísica do Poder. Rio de Janeiro: Graal, 1979, p 179192.

Paulo: Graal. 1979, p. 39-68.

Sobre a justiça popular. In:

- Microfísica do poder. 26 ed. São

Vigiar e punir: nascimento da prisão. 27. ed. Tradução de Raquel Ramalhete. Petrópolis, Vozes, 1987.

LAFER, Celso. A reconstrução dos direitos humanos: a contribuição de Hannah Arendt. Estudos avançados 11 (30), 1997. Acessado em 03 de novembro de 2017. Link: http://fabiopassos.com.br/downloads/919d1a8ac33158738d8f745e15305fe9.pdf.

MARX, Karl. In: Crítica Social. Brasil Adia. Rio de Janeiro. 2003

ROBAINA, Igor Martins Medeiros. Os Espaços Públicos e as Populações de Rua nas Grandes Metrópoles: Contenção Territorial e Estratégias Territoriais de Sobrevivência. Revista Geo-paisagem, São Paulo, v. 21, n. 11, jun. 2012. Disponível em: <http://www.feth.ggf.br/Metrópoles.htm>. Acesso em: 22 de agosto de 2015.

VASCONCELOS, Raquel Célia Silva de. Soberania versus Estado: crítica ao binômio poder-violência em Walter Benjamin. In: PULINO, Lúcia Helena; GADELHA, Sylvio (organizadores). Biopolítica, Escola e Resistência: infâncias para a formação de professores. São Paulo: Editora Alínea, 2012, p. 49-58.

\begin{tabular}{|c|c|c|c|c|}
\hline Rovista Dialectus & Ano 4 & n. 11 & Agosto - Dezembro 2017 & p. $145-157$ \\
\hline
\end{tabular}

